\title{
Research on the Teaching Reform of Segmentation Tai Chi of Colleges and Universities
}

\author{
Feng Yang ${ }^{1, a}$ \\ ${ }^{1}$ Xi'an International University, Shaanxi, Xi'an, China, 710077
}

Keywords: Teaching Reform, Segmentation Tai Chi, Colleges and Universities, Analysis

\begin{abstract}
At present, the Segmentation Tai Chi has become an important part of the physical education teaching system of many colleges and universities in our country. It has made important contributions to improving the physical fitness of college students and promoting the reform of physical education in vocational colleges. Under the influence of many factors, the overall effect of the new round of educational reform has not yet reached the established standard. Therefore, in order to combine the teaching experience for many years, in order to make the teaching model of the tattoo tai chi better apply to the sports training in colleges and universities, at the same time, in order to effectively solve the deficiencies of the tai chi teaching mode in colleges and universities, help colleges and universities to further improve the teaching quality of the tai chi in educational reform.
\end{abstract}

\section{Introduction}

Chinese institutions of higher learning to carry out section of Tai Chi training courses have been more than 30 years of history. But the puzzling phenomenon is that students like and popular traditional sports teaching courses, in recent years has been ignored, making students do not want to participate, teachers are doing nothing. Although many tai chi experts are closely concerned about the enthusiasm of the community enthusiastic fist, around the curriculum reform carried out various forms of scientific research activities and teaching activities, but the students of the tattoo tai chi training enthusiasm or growth in the trough. Especially in recent years to some foreign sports "invasion", many students began to invest and learn taekwondo, karate and so on. Although the institutions of higher learning have not yet Taekwondo as a formal physical education courses, but students of foreign martial arts enthusiasm and enthusiasm of the investment far more than Chinese martial arts. University is an important carrier of cultural transmission. College students are one of the important ways to inherit culture and develop culture. It is an important task and goal of how to cultivate tai chi tai chi tai chi culture.

\section{Analysis of the Factors Influencing the Spreading of Segmentation Tai Chi in Colleges and Universities}

The Course Is Old and Single and Students Are Not Interested in Learning. The course of teaching, teaching methods and teaching content is an important part of tattoo tai chi teaching. It will directly affect the teacher's teaching quality, and students interested in Tai Chi culture. Segmentation Tai Chi belongs to martial arts class, is the treasure of the Chinese nation's culture, has a very rich cultural resources, and by the majority of students love. However, the content of the teaching materials of the Tai Chi curriculum is monotonous and tedious, which is not only inconsistent with the rich content of Chinese martial arts, but also with the modern PE teaching colorful teaching activities and teaching content of the objective requirements cannot echo each other. In recent years, institutions of higher learning tai chi tai chi teaching by the "taekwondo", "karate" and other foreign sports culture. These shocks have objectively affected the enthusiasm of students to learn tattoo tai chi, and then it is further caused by the teaching of the curriculum crisis. According to the survey data show that the current students on the paragraph system tai chi teaching content dissatisfaction rate has reached $47.5 \%$, mostly due to the tattoo tai chi course is short, learning and more difficult, making the students difficult to grasp the proportion of dissatisfaction 
greatly improved. In addition, the institutions of higher learning tai chi tai chi teaching courses are generally used old-fashioned, rigid textbooks, and teachers of teaching means a single reflective is not strong, it is worrying that this phenomenon in the National University of Tai Chi teaching has been Ubiquitous [1].

Teachers in the Teaching Are Lacking Traditional Research and Blindly Teaching. It is well known that the teaching ability of the tai chi teacher is one of the important ways to stimulate students 'interest in learning and improve the quality of teaching and cultivate students' ability of lifelong training. At present, the majority of colleges and universities of the tai chi tai chi teacher groups are already young trend, they are basically from the major sports institutions. However, these young teachers basically learned only some of the optional teaching content, but the traditional Tai Chi project is not clear or even not practice. These teachers are basically using a fixed form of teaching methods, the only practice to participate in the game, and perennial practice of traditional routines, and admitted to the Vocational College of Wushu or even pure high school students, only learn five-step fist, junior Boxing, primary sword, simplified tai chi and so on.

The Characteristics of the Tattoo Tai Chi Are Contrary to College Students' Personality. Segmentation Tai Chi belongs to the inner boxing, in the lessons of Chinese classical philosophy on the basis of the formation of a internal and external practice, soft, slow boxing. And the tattoo tai chi tai chi is more emphasis on the practice of the form, generally require practitioners hand, eyes, body, and their own refined into one to shape the boxing, requiring practitioners to invest a lot of time and energy Feel the cultural charm of the tattoo tai chi. But for the personality of the avant-garde thinking of college students for the tattoo tai chi "chronic beauty" is not with badminton, football, basketball and other items to bring the dynamic and stimulating comparison. This greatly affected the Tai Chi in a large extent in the development of colleges and universities.

The Specific Sports Practice of the School Policy Constraints the Implementation of National Policy. After the comprehensive implementation of the country to deepen the reform of education measures, it is clear that the school's education should be all the health of the guiding ideology. In 2002, the Ministry of Education of China issued the "National Higher Education Curriculum Guide for Physical Education" clearly pointed out that the content of sports courses and guidance of the idea. In 2006, the Ministry of Education, the General Administration of Sports, promulgated the "Notice on Carrying out the National Sports of Sunny Students in China", which requires schools to implement and implement the "all student-oriented" educational concept of sustainable development and strengthen school sports Process, concerned about the movement of students. However, in 2010 the national student's physical and health survey results show that China's college students' physical quality and endurance showed a significant decline in the quality of the trend. A variety of situations have begun to show that, due to the current college students amateur choice of diversification, leading to the school's sports work is facing a very embarrassing situation, students of sports activities, time and energy less and less. Segmentation Tai Chi is one of the longest historical and cultural heritage of our country. It is a treasure of traditional Chinese culture. It gathers fitness, culture, nationality and cosmopolitanism. However, because of the physical education environment of the school, Activities to start the situation is not optimistic about the trend [2].

\section{The Strategy and Discussion on Improving the Teaching of Segmentation Tai Chi Classroom in University and College}

Actively Guide the Traditional Segmental Tai Chi Teaching Mode into the University, Create a New Textbook. The traditional tai chi is the most representative movement in our country. It has a rich cultural background and humanistic thought in the process of formation and development, has become a unique carrier of Chinese cultural spirit, and segmentation tai chi teaching is the inheritance, development and extension of traditional tai chi. According to the survey, the university's sports teaching materials are basically the same, are adapted to the development of modern sports routines.

In recent years, with the rapid development of sports culture, making "Taekwondo", "karate" in 
the university campus to flourish, which indirectly prompted the rapid reform of college physical education model. In addition to the improvement of teaching methods, it is necessary to make the teaching materials and teaching contents match each other in order to carry out the practice teaching of the tai chi. Therefore, colleges and universities should actively guide the traditional tai chi teaching mode into the classroom, through the practice of a variety of traditional routines to enhance the skills of tattoo tai chi to enhance the attractiveness of the course, but also increased student visits, They further understand and master the essence of Chinese tai chi culture and then better learning tattoo tai chi.

The traditional segmentation tai chi teaching content should create a new teaching mode to prepare new teaching materials, and to cultivate students' interests as the premise, to improve the overall quality of the purpose, in accordance with the principles of college physical education, and college students physical and psychological Characterized by the guiding ideology; the traditional tattoo tai chi tricks to improve the skills to achieve the normal number and skills of the difficulty. In this transformation under a set of more suitable for modern classroom teaching mode and extracurricular practice form was created in the content and style are more prominent, it is easy to learn and practice, so as to improve the traditional tattoo tai chi teaching materials and Model in the university's physical education system encountered in the popular situation.

Secondly, the new textbooks should fully answer and expand the process of "the development of Chinese tattoo tai chi", and closely combine the classroom teaching and establish the traditional tai chi tai chi routine and technical application through the paragraph evaluation method. Encourage students to actively study through the course to get the appropriate level of achievement and encourage them to learn a higher level of technical skills, update the traditional skill level to understand the deeper tai chi culture.

In short, the new textbooks should be in the project selection and content structure, highlighting the culture, ethnicity, tradition, and into the new ideas and innovation, so that students feel the Chinese tai chi culture profound, and the torsion tai chi endless charm, Lifelong exercise awareness and habits.

Strengthen the Professional Level of Teachers to Improve the Ability to Teach. According to the survey found that most of the university tattoo tai chi teachers are from the Institute of Physical Education, because these teachers have long been engaged in the work of the torsion tai chi training but in skills, style, etc. are still some deviation of understanding, so in the course Will directly affect the students on the paragraph system tai chi understanding, greatly reduce the students interest in learning, and even produce a boring feeling. Therefore, to improve the professional quality of the tai chi tai chi teacher, master the traditional Segmentation Tai Chi exercise and teaching ability, is currently teaching tai chi teacher to have.

Therefore, regular training of institutions of higher learning tai chi tai chi teacher training to improve the traditional tai chi teaching and teaching ability, will be a great help to the quality of teaching. But also through the University of Tai Chi teachers, experts and professors, the status of social hobby personnel, to carry out a series of sections of Tai Chi lectures and exchanges. Such as the origin or origin of Tai Chi and other content for the university and learning to pave the way, so that tai chi teacher can further improve the tattoo system Tai Chi skills and culture in-depth understanding.

Vigorously Promote the Segmentation Tai Chi Segment into the University to Stimulate Students to Obtain the Enthusiasm of the Paragraph. "China's martial arts segment system is to enhance people's physique, and thus promote the development of martial arts, improve the level of martial arts technology and theoretical standards at the same time the establishment of a national martial arts system." Part of the martial arts in Shanghai part of the system has long been a very good implementation, in the implementation process has also achieved very good results. "There are thousands of college students attending the" Chinese Wushu Segmentation System "in every session of Shanghai University. So far, 3939 students have passed this assessment and have obtained the certificate and emblem. The course is a line of virtue and technology Shuangxiu parallel courses, but also a traditional Chinese etiquette courses, paragraph system is an important symbol of its 
measurement. Therefore, colleges and universities should learn from and learn from the experience of Shanghai universities, take a variety of measures to actively guide students to obtain paragraph system [3].

\section{Conclusion}

Excellent culture can only get innovation and development on the basis of heritage, as a treasure of traditional Chinese culture, tai chi culture derived the tattoo tai chi culture, colleges and universities must seize the essence in the training. Paying attention to the heritage and development of Segmentation Tai Chi culture in the university, taking a variety of measures to promote the contributions of tattoo tai chi culture in the education are the responsibility of cultivating talent in colleges and universities. Effective construction of university tai chi culture development is the historical mission the college.

\section{Acknowledgements}

Fund Project: 2015 Xi'an Foreign Affairs Institute the second batch of higher education teaching reform research project: practice and research on the introduction of Taijiquan segmentation teaching in medical personnel training (2015B31)

The Stage Research Results of 2016 Annual Shaanxi Provincial Department of Education Research Project: Experimental Study of Taijiquan Segment System Teaching Embedded in Medical Students Personnel Training (16JK2166).

\section{References}

[1] Liu Shuhui. Study on the Feasibility of Developing Wushu Sectional Teaching Course in Colleges and Universities [J]. Journal of Guangzhou Physical Education Institute, 2013, 02: 112-116.

[2] Zhang Yunlong, Lin Dasheng.Study on the practice of teaching reform of "segment system" of martial arts in colleges and universities - Taking Shanghai University as an example [J]. Journal of Nanjing Institute of Physical Education (Social Science Edition), 2010, 06: 97-100

[3] Wang Chongfei. Higher vocational college tai chi section of the teaching reform[J]. Contemporary sports science and technology, 2014, 04: 69 -71 